\title{
Short communication: Genetic parameters for measures of calf health in a population of Holstein calves in New York State
}

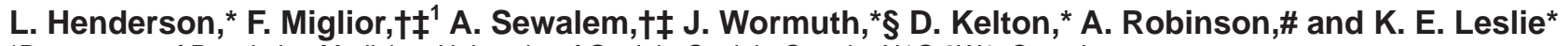 \\ *Department of Population Medicine, University of Guelph, Guelph, Ontario, N1G 2W1, Canada \\ †Guelph Food Research Centre, Agriculture and Agri-Food Canada, Guelph, Ontario, N1G 5C9, Canada \\ $\ddagger$ Canadian Dairy Network, Guelph, Ontario, N1K 1E5, Canada \\ §Red Oak Agriculture and CY Heifer Farm, PO Box 275, Elba, NY 14058 \\ \#Department of Animal and Poultry Science, University of Guelph, Guelph, Ontario, N1G 2W1, Canada
}

ABSTRACT

The objectives of this study were to estimate the genetic parameters of preweaning undifferentiated bovine respiratory disease (BRD), umbilical diseases (UMB), and bloat (BLT) for a population of Holstein calves from New York State, as well as to associate the estimated breeding values determined in the current study with traits from ongoing genetic evaluations used in Canada and the United States. Data were recorded for 7,372 heifer calves at a commercial rearing facility in New York State, from arrival at 1 to $7 \mathrm{~d}$ of age for the duration of stay at the facility. Performance and disease up to weaning and mortality before and after weaning were recorded. The 3 traits of interest, BRD, UMB, and BLT, were scored as 0 or 1 and analyzed using a multivariate linear sire model. The model included fixed effects of arrival weight, serum total protein, weaning weight, and season and year of birth; herd and sire were included as random effects. The heritabilities of the 3 health traits of interest were estimated at 0.09 for BRD, 0.14 for UMB, and 0.04 for BLT. The genetic correlation between the calf health traits BRD and BLT was 0.62. Correlations between BRD and UMB and between BLT and UMB were close to zero. Breeding values were estimated for the 3 calf health traits and correlated with routinely evaluated traits from Canadian and US genetic evaluations (correlations ranged from -0.42 to 0.32). Significant differences existed among Holstein sires for calf health during the preweaning period.

Key words: calf health, variance component estimation, multiple-trait model

Received March 7, 2011

Accepted August 23, 2011.

${ }^{1}$ Corresponding author: miglior@cdn.ca

\section{Short Communication}

In the past decade, the possibility of using genetic selection as a tool for improving disease resistance in dairy cattle has been evaluated by researchers and producers alike. Specifically, many studies have investigated the influence of genetics in common diseases of the dairy cow (Lyons et al., 1991; Uribe et al., 1995; Zwald et al., 2004; Heringstad et al., 2005). To date, limited research has been published on the genetic effects of common diseases in dairy calves. The few published studies pertaining to this topic have focused on the genetics of respiratory disease and diarrhea in Norwegian Red (Heringstad et al., 2008) and Austrian Fleckvieh calves (Fuerst-Waltl et al., 2010) and of respiratory disease in various breeds of beef calves (Muggli-Cockett et al., 1992; Snowder et al., 2005).

Preweaning calf diseases have been associated with increased risk of morbidity later in the rearing period and are likely to have an effect on the mature life of the animal, such as increased age at first calving and decreased lifetime profitability (Waltner-Toews et al., 1986; Svensson et al., 2006). In addition, calfhood diarrhea has been associated with decreased first-lactation milk production (Svensson and Hultgren, 2008). The occurrence of neonatal calf diarrhea is strongly associated with respiratory disease, which is known to have longer convalescence and profound effects on rate of growth (Lundborg et al., 2003). In a recent report, heifers that experienced bovine respiratory disease (BRD) before first calving had 1.9 greater odds of not completing the first lactation than those that never experienced BRD (Bach, 2011). In the current study, we were optimistic about the potential to forecast future heifer success in finishing the first lactation based on average daily gain early in life, incidence of $\mathrm{BRD}$, reproductive performance, and age at first calving. In spite of the reported low heritabilities of most health traits, genetic variation of calfhood disease is of potential economic importance. As such, inclusion of these traits in breeding programs could be valuable. To date, the only routinely evaluated 
traits that include information concerning calves in $\mathrm{Ca}$ nadian and US national dairy cattle breeding programs are calf survival and stillbirth, respectively. Recently, we published estimates of the genetic parameters of survival to weaning and survival to exit for a population of Holstein calves from a commercial heifer rearing operation in New York State (NY), and have associated these EBV with traits from ongoing genetic evaluations used in Canada and the United States (Henderson et al., 2011). These results suggest that significant genetic differences exist among Holstein sires for calf survival to weaning and through the growing period. The objectives of the current research were to estimate genetic parameters for 3 preweaning diseases: BRD, umbilical diseases (UMB), and bloat (BLT), for a population of calves from the same population of calves in NY, and to associate EBV for the 3 calf heath traits with traits routinely evaluated in Canada and United States.

The commercial heifer raising facility (CY) that participated in this investigation is located in upstate New York. Annually, this farm raises approximately 4,000 heifers to varying target ages based on the contractual arrangement between the facility and the farm of origin. The rearing process at this facility, as well as the editing of the records provided by CY heifer farm, have been described in detail by Henderson et al. (2011). Data for the analysis spanned from 1998 to 2008 and, after editing, consisted of 7,372 Holstein calf records from 36 herds sired by 264 bulls. Average number of daughters per sire was 28 and maximum number of daughters per sire was 164 .

Data for all incidences of disease and treatments administered were entered according to standard farm protocols for each condition. These data were recorded using consistent notations in the farm DairyComp 305 (Valley Ag Software, Tulare, CA) records. These standard diagnosis and treatment protocols were established by the farm management and herd health management advisory teams. Review of the protocols was carried out on a regular basis and as specific herdlevel health concerns occurred. All farm personnel were trained in the use of these protocols. For the purposes of the current study, diseases events from arrival of the calf until weaning were collected. Average age at weaning was $47.3 \mathrm{~d}$ (SD of 8.6). Diseases included in the analysis were undifferentiated BRD, UMB, and BLT. Disease prevalences in the population were $38.4 \%$ for BRD, $4.4 \%$ for BLT, and $6.2 \%$ for UMB. Because the majority of the calves at this heifer rearing facility were treated prophylactically for neonatal calf diarrhea $(60.1 \%)$, it was decided that this condition would not be included in the analysis.

Bovine respiratory disease, UMB, and BLT were each defined as a binary trait $(1=$ disease and 0 otherwise $)$ based on whether or not the calf was treated for the disease during the preweaning period. A multiple-trait linear sire model was used in which the 3 disease traits were each considered as a separate trait. The pedigree file included 749 bulls. The following model was used for genetic parameter estimation:

$$
Y_{i j k l m}=h y_{i}+W_{j}+P_{k}+S_{l}+\text { sire }_{m}+e_{i j k l m},
$$

where $Y_{i j k l m}$ is the observation (0 or 1 ) for each calf health trait, $h y$ is the random effect of herd of originyear of birth (84 classes), $W_{j}$ is the fixed effect of arrival weight group with 5 classes $(1=22-33 \mathrm{~kg} ; 2=34-37$ $\mathrm{kg} ; 3=38-41 \mathrm{~kg} ; 4=42-46 \mathrm{~kg} ; 5=\geq 47 \mathrm{~kg}$ ), $P_{k}$ is the fixed effect of total serum protein concentration (indicator of supplied colostrum) with 4 classes $(1=30-49$ $\mathrm{g} / \mathrm{L} ; 2=50-59 \mathrm{~g} / \mathrm{L} ; 3=60-69 \mathrm{~g} / \mathrm{L} ; 4=70-80 \mathrm{~g} / \mathrm{L})$, $S_{l}$ is the fixed effect for season of birth (seasons were January to March, April to June, July to September, October to December), sire $_{m}$ is the random additive genetic effect of sire of the calf, and $e$ is the random effect of residual. In matrix form, the multiple-trait sire model can be described as

$$
\mathbf{Y}=\mathbf{X b}+\mathbf{Z}_{1} \mathbf{h y}+\mathbf{Z}_{2} \mathbf{a}+\mathbf{e},
$$

where $\mathbf{Y}$ is the matrix of the observations for the 3 traits; $\mathbf{X}, \mathbf{Z}_{1}$, and $\mathbf{Z}_{2}$ are the incidence matrices relating the observations to the fixed and random herd-year and sire effects, respectively; $\mathbf{b}$ is a vector of fixed effects (including arrival weight group, total serum protein group, and season of birth); hy is the vector of random herd-year effects; $\mathbf{a}$ is the vector of random genetic effects of sire of calf; and $\mathbf{e}$ is the vector of random residual effects. The expectations $(\mathbf{E})$ and assumed variances $(\mathbf{V})$ were $\mathbf{E}(\mathbf{y})=\mathbf{X b} ; \mathbf{E}(\mathbf{h y})=\mathbf{E}(\mathbf{a})=\mathbf{E}(\mathbf{e})$ $=0 ; \mathbf{V}(\mathbf{h y})=\mathbf{H Y} ; \mathbf{V}(\mathbf{a})=\mathbf{G} ; \mathbf{V}(\mathbf{e})=\mathbf{R} ; \operatorname{cov}\left(\mathbf{a}, \mathbf{e}^{\mathbf{\prime}}\right)$ $=0$; and $\mathbf{V}(\mathbf{y})=\mathbf{Z G Z}+\mathbf{H Y}+\mathbf{R}$, where $\mathbf{H Y}$ is the direct product of an identity matrix $(\mathbf{I})$ of order of the number of herd-years and the matrix of herd-year variances $\left(\mathbf{I} \otimes \mathbf{h} \mathbf{y}_{\mathbf{0}}\right) ; \mathbf{G}$ is the direct product of the numerator relationship matrix $(\mathbf{A})$ for sires and the matrix of genetic variance and covariances $\left(A \otimes \mathbf{G}_{0}\right)$; and $\mathbf{R}$ is the direct product of an identity matrix of order of the number of observations and the matrix of error variances and covariances $\left(\mathbf{I} \otimes \mathbf{R}_{\mathbf{0}}\right)$. Heritability values were calculated using

$$
h^{2}=4 \sigma_{\text {sire }}^{2} /\left(\sigma_{\text {sire }}^{2}+\sigma_{h y}^{2}+\sigma_{e}^{2}\right) .
$$

(Co)variance components were estimated using REML implemented in the DMU software package with 
an expectation-maximization algorithm multivariate mixed model analysis (Madsen and Jensen, 2006).

Genetic parameters obtained from the linear model were used for the breeding values estimation procedure. The EBV obtained from the multiple-trait sire model were used for correlation analyses, with EBV or PTA for traits of economics importance obtained from the national genetic evaluation of Canada (performed by Canadian Dairy Network, Guelph, ON) and the United States (performed by Animal Improvement Programs Laboratory of USDA, Beltsville, MD, and by Holstein USA, Brattleboro, VT). For the purposes of this study, a calf was considered healthy if it did not receive treatment for that particular disease during the preweaning period. Sign of sire solutions from the sire model was reversed; thus, high sire EBV were more desirable as they indicated increased disease resistance in this study. Details of routine genetic evaluation in Canada and the United States can be found at the Interbull website (Interbull, 2011). For correlations with US traits, multi-trait across country evaluations on the US scale (analyzed by Interbull) were used.

The incidence of BRD (38.4\%) in the current study was moderately high, with a previous disease incidence of $15 \%$ having been reported (Waltner-Toews et al., 1986). The incidence of umbilical disease reported in the literature is markedly variable. For example, in another population of calves in NY, umbilical disease and umbilical hernia were reported at 14 and $15 \%$, respectively (Virtala et al., 1996). These rates are higher than in the current study population (6.2\%). However, the rates of disease in this population are similar to those described in a synopsis of calf health (Radostits et al., 2007)

Estimates of sire, herd-year, residual, and total variances for each of the 3 calf health traits are provided in Table 1. Estimates of heritabilities, genetic correlations, and residual correlations and their SE are provided in Table 2. Heritability estimates for BRD, BLT, and UMB were 0.09, 0.04, and 0.14, respectively. The heritability estimate for BRD was higher than the previously estimated heritability (0.05) for this disease in Norwegian Red calves (Heringstad et al., 2008).
However, the heritability estimate by Heringstad et al. (2008) is expressed in the underlying scale and is not directly comparable to our estimate, because heritability estimates from linear models (our study) were dependent on disease incidence, and Heringstad et al. (2008) used instead a threshold model, which removes the dependency between location and dispersion parameters. In a study on respiratory disease in beef breeds, heritabilities using linear models ranged from 0.00 to 0.26 , depending on the yearly incidence of the illness (Snowder et al., 2005). To our knowledge, heritabilities for umbilical disease and bloat in dairy calves have not been previously reported in the literature. Correlations between UMB and BRD as well as those between UMB and BLT were estimated to be close to zero. Conversely, the genetic correlation between BRD and BLT was positive and moderately high (0.62). This result could be due to the adverse effect that BRD may have on the vagus nerve. Calves that have suffered BRD intermittently develop BLT from damage to the thoracic portion of the vagus nerve or enlarged thoracic lymph nodes that cause failure of eructation, problems swallowing, and compromised forestomach motility (Divers and Peek, 2008). Over time, it is possible that selection for decreased incidence of either of these diseases would result in a decreased incidence of the other, as an effect of the moderately high genetic correlation between them.

Estimated breeding values for all sires were computed and standardized to a mean of 100 and an SD of 5 for each of the calf health traits. Reliabilities of EBV were not computed and were expected to be low, especially for the least heritable trait (BLT) and for those sires with the smallest number of daughters reared at CY heifer farm. Figure 1 illustrates the distributions of the multiple-trait EBV by phenotypic daughter averages for resistance to BRD, BLT, and UMB. The coefficient of determination $\left(\mathrm{R}^{2}\right)$ was found to be greater for EBV for UMB (0.630) than for BRD (0.367) or BLT (0.354).

Correlations between EBV of the 3 calf health traits of interest and routinely evaluated Canadian and US traits were determined. All correlations that were found to be significant $(P \leq 0.05)$ with EBV for routinely

Table 1. Sire $\left(\sigma_{\text {sire }}^{2}\right)$, herd-year $\left(\sigma_{h y}^{2}\right)$, residual $\left(\sigma_{e}^{2}\right)$, and total variances for the 3 calf health traits of interest (asymptotic SD in parentheses)

\begin{tabular}{lcccc}
\hline $\begin{array}{l}\text { Calf } \\
\text { health trait }\end{array}$ & $\sigma_{\text {sire }}^{2}$ & $\sigma_{h y}^{2}$ & $\sigma_{e}^{2}$ & Total \\
\hline BRD & $0.005(0.0012)$ & $0.028(0.0060)$ & $0.197(0.0033)$ & 0.231 \\
BLT & $0.001(0.0002)$ & $0.005(0.0012)$ & $0.039(0.0007)$ & 0.045 \\
UMB & $0.002(0.0005)$ & $0.004(0.0010)$ & $0.053(0.0009)$ & 0.059 \\
\hline
\end{tabular}

${ }^{1} \mathrm{BRD}=$ undifferentiated bovine respiratory diseases; $\mathrm{BLT}=$ bloat disease; UMB = umbilical disease. 
Table 2. Heritabilities (on diagonal), genetic correlations (above diagonal), and residual correlations (below diagonal) for the 3 calf health traits (SE in parentheses)

\begin{tabular}{lrrr}
\hline $\begin{array}{l}\text { Calf } \\
\text { health trait }\end{array}{ }^{1}$ & \multicolumn{1}{c}{} & \multicolumn{1}{c}{ BLT } & \multicolumn{1}{c}{ UMB } \\
\hline BRD & $0.095(0.037)$ & $0.625(0.198)$ & $-0.027(0.016)$ \\
BLT & $0.011(0.012)$ & $0.040(0.019)$ & $-0.066(0.035)$ \\
UMB & $-0.011(0.017)$ & $-0.015(0.013)$ & $0.139(0.085)$ \\
\hline
\end{tabular}

${ }^{1} \mathrm{BRD}=$ undifferentiated bovine respiratory diseases; $\mathrm{BLT}=$ bloat disease; UMB $=$ umbilical disease.

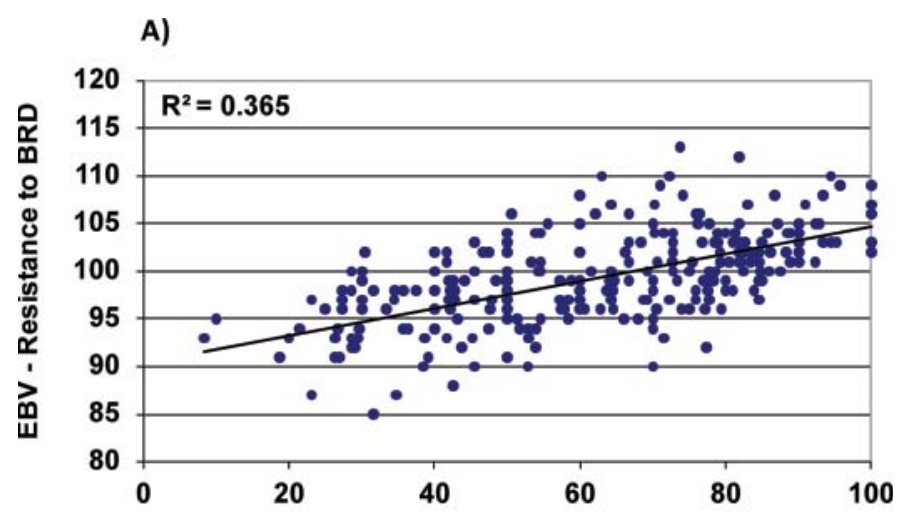

B)

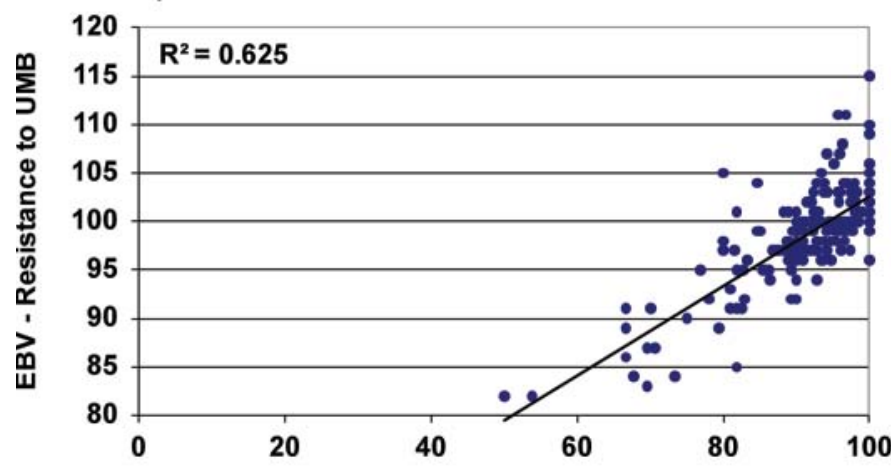

C)

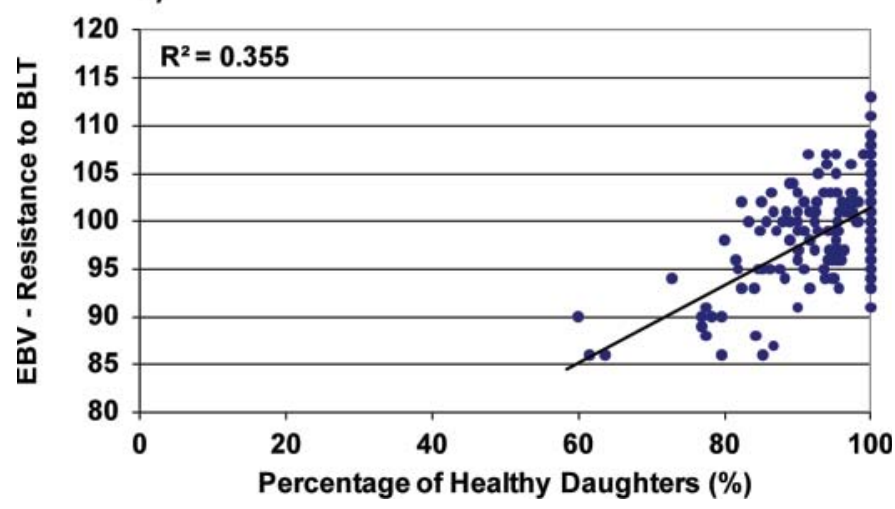

Figure 1. Distribution of sire EBV by average percentage of healthy daughters for $(\mathrm{A})$ resistance to undifferentiated bovine respiratory diseases (BRD); (B) resistance to umbilical disease (UMB); (C) resistance to bloat (BLT). Color version available in the online PDF. evaluated Canadian traits are presented in Table 3 and those with PTA for routinely evaluated US traits are presented in Table 4, ranging from -0.42 to 0.30 . Bovine respiratory disease and BLT were significantly correlated with many routinely evaluated traits in both countries. Repeatedly, these correlations were of a similar direction and magnitude due to the moderately high genetic correlation between the 2 traits. Some of the associations between EBV for calf health traits and routinely evaluated traits make biological sense and are logically plausible. On the other hand, the associations between calf health traits and some routinely evaluated traits; for instance, udder conformation traits and workability, are more difficult to rationalize. The size and robust nature of the current data set may have resulted in the detection of some spurious associations. Nevertheless, further investigation of these associations is warranted.

Dairy strength, stature, and height at front end are routinely evaluated Canadian body conformation traits that were all found to be negatively correlated with at least 1 of the 3 calf health traits of interest. Similarly, these associations existed between the EBV for the calf health traits and PTA for routinely evaluated body traits in the United States. These associations indicate that calves sired by bulls with high PTA for linear body size conformation traits may be more likely to experience preweaning disease than calves sired by bulls with lower PTA for these traits. Heavy calves with large body dimensions are most likely sired by bulls with high PTA for body size, because these traits are highly heritable (Foster et al., 1988). The negative association of PTA for body size conformation traits with preweaning BRD and BLT may be due to the relationship between calf size and calving ease, with heavier calves experiencing more dystocia (Sieber et al., 1989). As a result of calving difficulties associated with higher birth weights, heavier calves may have more health issues in early life than calves born easily.

Some of the strongest negative correlations were estimated between EBV for the calf health traits and the routinely evaluated Canadian trait "angularity" and the routinely evaluated US trait "dairy form." For BRD and BLT, significant negative genetic correlations 
Table 3. Significant $(P \leq 0.05)$ correlations between EBV for the 3 calf health traits and EBV for traits routinely evaluated by Canadian Dairy Network (Guelph, ON)

\begin{tabular}{|c|c|c|c|c|}
\hline $\begin{array}{l}\text { Routinely } \\
\text { evaluated trait }\end{array}$ & $\begin{array}{l}\text { Sires } \\
\text { (no.) }\end{array}$ & BRD & BLT & UMB \\
\hline \multicolumn{5}{|l|}{ Production } \\
\hline Fat $(\%)$ & 133 & -0.20 & - & - \\
\hline Fat $(\mathrm{kg})$, first parity & 133 & -0.21 & - & - \\
\hline Persistency, first parity & 133 & - & - & -0.17 \\
\hline \multicolumn{5}{|l|}{ Workability } \\
\hline Milking temperament & 127 & -0.21 & -0.20 & 0.19 \\
\hline \multicolumn{5}{|l|}{ Reproduction (heifer) } \\
\hline Age at first service & 128 & -0.24 & - & - \\
\hline \multicolumn{5}{|l|}{ Reproduction (cow) } \\
\hline 56-d nonreturn rate & 123 & 0.26 & 0.29 & - \\
\hline First service to conception & 123 & 0.24 & 0.32 & - \\
\hline Days open & 123 & 0.23 & 0.30 & - \\
\hline Calf survival & 123 & 0.19 & - & - \\
\hline Daughter fertility & 128 & 0.24 & 0.29 & - \\
\hline \multicolumn{5}{|l|}{ Conformation } \\
\hline Conformation & 124 & -0.19 & -0.24 & - \\
\hline Mammary system & 124 & - & -0.20 & - \\
\hline Dairy strength & 124 & -0.31 & -0.28 & - \\
\hline Height at front end & 124 & -0.21 & - & - \\
\hline Stature & 124 & -0.33 & -0.30 & - \\
\hline Angularity & 124 & -0.42 & -0.39 & - \\
\hline Udder texture & 124 & -0.23 & -0.26 & - \\
\hline Median suspensory & 124 & -0.16 & -0.20 & - \\
\hline Fore attachment & 124 & - & - & 0.19 \\
\hline Rear attachment width & 124 & -0.18 & -0.24 & - \\
\hline Heel depth & 124 & 0.18 & - & - \\
\hline Bone quality & 124 & -0.24 & -0.22 & - \\
\hline
\end{tabular}

${ }^{1} \mathrm{BRD}=$ undifferentiated bovine respiratory diseases; BLT $=$ bloat disease; UMB $=$ umbilical disease.

of -0.42 and -0.39 were found with angularity, and -0.30 and -0.25 with dairy form, respectively. These negative associations indicate that bulls with high evaluations for angularity or dairy form sire calves that are more likely to experience BRD and BLT during the preweaning period compared with bulls with lower evaluations for these traits. Previous literature has speculated that selection for angularity has affected the physical appearance of the cow as well as physiological functions (Hansen, 2000). Furthermore, favorable

Table 4. Significant $(P \leq 0.05)$ correlations between EBV for the 3 calf health traits and PTA for traits routinely evaluated by the USDA Animal Improvement Programs Laboratory (Beltsville, MD) and the Holstein Association USA (Brattleboro, VT)

\begin{tabular}{|c|c|c|c|c|}
\hline $\begin{array}{l}\text { Routinely } \\
\text { evaluated trait }\end{array}$ & $\begin{array}{l}\text { Sires } \\
\text { (no.) }\end{array}$ & BRD & BLT & UMB \\
\hline \multicolumn{5}{|l|}{ Production } \\
\hline Fat $(\mathrm{kg})$ & 228 & -0.17 & - & - \\
\hline \multicolumn{5}{|l|}{ Reproduction } \\
\hline Daughter pregnancy rate & 221 & 0.15 & 0.19 & - \\
\hline \multicolumn{5}{|l|}{ Conformation } \\
\hline Final score & 217 & -0.26 & -0.28 & - \\
\hline Udder composite & 217 & -0.19 & -0.24 & 0.16 \\
\hline Feet and leg composite & 217 & - & -0.16 & - \\
\hline Stature & 217 & -0.27 & -0.23 & - \\
\hline Body depth & 217 & -0.21 & -0.17 & - \\
\hline Dairy form & 217 & -0.30 & -0.25 & - \\
\hline Thurl width & 217 & -0.20 & -0.20 & - \\
\hline Fore udder attachment & 217 & -0.16 & -0.22 & 0.17 \\
\hline Rear udder height & 217 & -0.20 & -0.25 & 0.22 \\
\hline Udder cleft & 217 & -0.14 & - & - \\
\hline Udder depth & 217 & - & -0.17 & - \\
\hline Mobility & 217 & - & -0.16 & - \\
\hline Rear legs rear view & 217 & - & -0.15 & - \\
\hline \multicolumn{5}{|l|}{ Longevity } \\
\hline Direct productive life & 212 & 0.17 & 0.19 & - \\
\hline
\end{tabular}

${ }^{1} \mathrm{BRD}=$ undifferentiated bovine respiratory diseases; $\mathrm{BLT}=$ bloat disease; UMB = umbilical disease. 
emphasis on cows that appear sharper (more angular) might result in cows that are more prone to metabolic problems. Dairy form is found to be strongly negatively correlated with BCS (Lassen et al., 2003). The associations in the current research indicate that unfavorable consequences of selection for angularity and dairy form may exist at the calf level as well.

First service to conception, 56-d nonreturn rate, days open, and daughter fertility are routinely evaluated Canadian EBV for reproduction that were significant and desirably correlated with EBV for BRD and BLT. In addition, the US fertility trait daughter pregnancy rate was desirably associated with BRD and BLT; therefore, as the EBV for daughter pregnancy rate increases, EBV for BRD and BLT increase. The biological reasoning between these associations may not be obvious. However, the positive correlations between calf health traits and reproduction traits in the current study may be explained by evidence that rate of growth and measures of calf health are reflected in future milk production, reproductive performance, and herd life (van der FelsKlerx et al., 2002; Soberon et al., 2009). The occurrence of BRD has been associated with a dramatic decrease in growth. Each week of diagnosed pneumonia may reduce total BW gain during the first 3 mo by around $1 \mathrm{~kg} /$ wk (Virtala et al., 1996).

Significant genetic variation between sires exists for the health of their calves from birth to weaning. Heritabilities of calf health traits were low. However, the heritability for BRD was higher in the current study than has previously been reported in dairy calves. The genetic correlation between BRD and BLT was moderately high, likely due to the negative effect BRD may have on the vagus nerve, consequently influencing the occurrence of BLT. Associations between the EBV for the 3 calf health traits of interest and routinely evaluated traits in Canada and the United States were found to be significant for several traits. Specifically, many linear body size conformation traits were negatively correlated with calf health traits. In addition, numerous reproduction traits were positively correlated with the same calf health traits. Further research into the genetic mechanisms of disease resistance in calves is warranted.

\section{ACKNOWLEDGMENTS}

The authors acknowledge the management and staff at CY Heifer Farm for their invaluable contribution to this research. Funding was provided by the DairyGEN Council of the Canadian Dairy Network (Guelph, ON, Canada) and the National Science and Engineering Research Council of Canada (Ottawa, ON, Canada). Finally, the authors acknowledge the Animal Improve- ment Programs Laboratory (AIPL, USDA, Beltsville, MD) and the Holstein Association USA (Brattleboro, VT) for their kindness in allowing use of multiple-trait across-country evaluation PTA expressed on the US scale. Finally, we thank the two anonymous reviewers for their helpful suggestions and comments.

\section{REFERENCES}

Bach, A. 2011. Associations between several aspects of heifer development and dairy cow survivability to second lactation. J. Dairy Sci. 94:1052-1057.

Divers, T., and S. Peek. 2008. Chronic bloat. Pages 139-141 in Rebhun's Diseases of Dairy Cattle. 2nd ed. Elsevier Inc., St. Louis, MO.

Foster, W. W., A. E. Freeman, P. J. Berger, and A. Kuck. 1988. Linear type trait analysis with genetic parameter estimation. J. Dairy Sci. $71: 223-231$.

Fuerst-Waltl, B., A. Koeck, C. Fuerst, and C. Egger-Danner. 2010. Genetic analysis of diarrhea and respiratory diseases in Austrian Fleckvieh heifer calves. Article No. 304 in Proc. 9th World Congr. Genet. Appl. Livest. Prod., Leipzig, Germany. CD-ROM Communication PP4-138.

Hansen, L. B. 2000. Consequences of selection for milk yield from a geneticist's viewpoint. J. Dairy Sci. 83:1145-1150.

Henderson, L., F. Miglior, A. Sewalem, D. Kelton, A. Robinson, and K. Leslie. 2011. Estimation of genetic parameters for measures of calf survival in a population of Holstein dairy calves in New York State. J. Dairy Sci. 94:461-470.

Heringstad, B., Y. M. Chang, D. Gianola, and G. Klemetsdal. 2005 Genetic analysis of clinical mastitis, milk fever, ketosis, and retained placenta in three lactations of Norwegian Red cows. J. Dairy Sci. 88:3273-3281.

Heringstad, B., Y. M. Chang, D. Gianola, and O. Osteras. 2008. Genetic analysis of respiratory disease in Norwegian Red calves. J. Dairy Sci. 91:367-370.

Interbull. 2011. National GES information. Accessed Jan. 22, 2011. http://www-interbull.slu.se/national_ges_info2/framesida-ges. htm.

Lassen, J., M. Hansen, M. K. Sorensen, G. P. Aamand, L. G. Christensen, and P. Madsen. 2003. Genetic relationship between body condition score, dairy character, mastitis, and diseases other than mastitis in first-parity Danish Holstein cows. J. Dairy Sci. $86: 3730-3735$.

Lundborg, G. K., P. A. Oltenacu, D. O. Maizon, E. C. Svensson, and P. G. A. Liberg. 2003. Dam-related effects on heart girth at birth, morbidity and growth rate from birth to 90 days of age in Swedish dairy calves. Prev. Vet. Med. 60:175-190.

Lyons, D. T., A. E. Freeman, and A. L. Kuck. 1991. Genetics of health traits in Holstein cattle. J. Dairy Sci. 74:1092-1100.

Madsen, P., and J. Jensen. 2006. A User's Guide to DMU, A package for analyzing multivariate mixed models. Version 6, release 4.6 . Department of Genetics and Biotechnology, Faculty of Agricultural Sciences (DJF), Research Centre Foulum, Tjele, Denmark.

Muggli-Cockett, N. E., L. V. Cundiff, and K. E. Gregory. 1992. Genetic analysis of bovine respiratory disease in beef calves during the first year of life. J. Anim. Sci. 70:2013-2019.

Radostits, O. M., C. C. Gay, K. W. Hinchcliff, and P. D. Constable, ed. 2007. Veterinary Medicine: A Textbook of the Diseases of Cattle, Sheep, Pigs, Goats and Horses. 10th ed. Saunders Elsevier, Philadelphia, PA.

Sieber, M., A. E. Freeman, and D. H. Kelley. 1989. Effects of body measurements and weight on calf size and calving difficulty of Holsteins. J. Dairy Sci. 72:2402-2410.

Snowder, G. D., L. D. Van Vleck, L. V. Cundiff, and G. L. Bennett. 2005. Influence of breed, heterozygosity, and disease incidence on estimates of variance components of respiratory disease in preweaned beef calves. J. Anim. Sci. 83:1247-1261. 
Soberon, F., E. Raffrenato, R. W. Everett, and M. E. Van Amburgh. 2009. Early life management and long term productivity of dairy calves. J. Dairy Sci. 92(E-Suppl. 1):238. (Abstr.)

Svensson, C., and J. Hultgren. 2008. Associations between housing, management, and morbidity during rearing and subsequent firstlactation milk production of dairy cows in southwest Sweden. J. Dairy Sci. 91:1510-1518.

Svensson, C., A. Linder, and S. O. Olsson. 2006. Mortality in Swedish dairy calves and replacement heifers. J. Dairy Sci. 89:4769-4777.

Uribe, H. A., B. W. Kennedy, S. W. Martin, and D. F. Kelton. 1995. Genetic parameters for common health disorders of Holstein cows. J. Dairy Sci. 78:421-430.

van der Fels-Klerx, H. J., H. W. Saatkamp, J. Verhoeff, and A. A. Dijkhuizen. 2002. Effects of bovine respiratory disease on the pro- ductivity of dairy heifers quantified by experts. Livest. Prod. Sci $75: 157-166$

Virtala, A. M. K., G. D. Mechor, Y. T. Grohn, and H. N. Erb. 1996. The effect of calfhood diseases on growth of female dairy calves during the first 3 months of life in New York State. J. Dairy Sci. 79:1040-1049.

Waltner-Toews, D., S. W. Martin, A. H. Meek, and I. McMillan. 1986 Dairy calf management, morbidity and mortality in Ontario Holstein herds. I. The data. Prev. Vet. Med. 4:103-124.

Zwald, N. R., K. A. Weigel, Y. M. Chang, R. D. Welper, and J. S. Clay. 2004. Genetic selection for health traits using producerrecorded data. I. Incidence rates, heritability estimates, and sire breeding values. J. Dairy Sci. 87:4287-4294. 